\title{
Vacuum Surface Flashover and High Pressure Gas Streamers
}

Federal Manufacturing \& Technologies

J. M. Elizondo, M. L. Krogh, D. Smith,

D. Stoltz, and S. N. Wright, FM\&T, and

S. E. Sampayan, G. J. Caporaso, P. Vitello,

and N. Tishchenko, Lawrence Livermore National Laboratory

\section{KCP-613-5970}

\section{Published July 1997}

$$
\text { CONF- } 9706113 \ldots
$$

Approved for public release; distribution is unlimited.

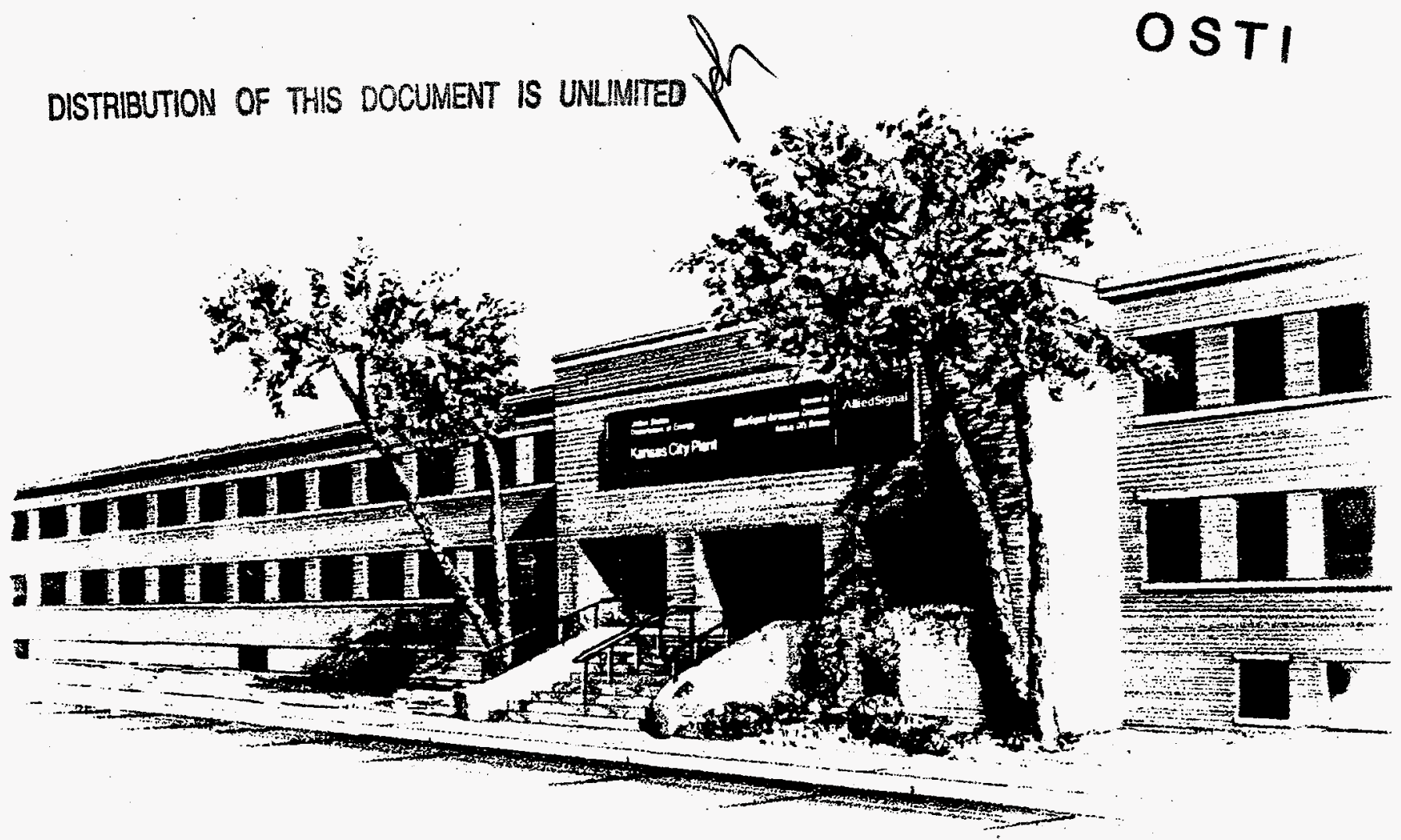

Prepared Under Contract Number DE-ACO4-76-DP00613 for the United States Department of Energy
MASTER

RECEIVED

JUL $1{ }^{4} 1997$

OSTI 


\section{DISCLAIMER}

Portions of this document may be illegible electronic image products. Images are produced from the best available original document. 


\section{DISCLAIMER}

This report was prepared as an account of work sponsored by an agency of the United States Government. Neither the United States Government nor any agency thereof, nor any of their employees, makes any warranty, express or implied, or assumes any legal liability or responsibility for the accuracy, completeness, or usefulness of any information, apparatus, product, or process disclosed, or represents that its use would not infringe privately owned rights. Reference herein to any specific commercial product, process, or service by trade names, trademark, manufacturer, or otherwise, does not necessarily constitute or imply its endorsement, recommendation, or favoring by the United States Government or any agency thereof. The views and opinions of authors expressed herein do not necessarily state or reflect those of the United States Government or any agency thereof.

Printed in the United States of America.

This report has been reproduced from the best available copy.

Available to DOE and DOE contractors from the Office of Scientific and Technical Information, P. O. Box 62, Oak Ridge, Tennessee 37831 ; prices available from (615) 576-8401, FTS 626-8401.

Available to the public from the National Technical Information Service, U. S. Department of Commerce, 5285 Port Royal Rd., Springfield, Virginia 22161.

Copyright $\odot 1997$ by AlliedSignal Inc. The Government is granted for itself and others acting on its behalf a paid-up, nonexclusive, irrevocable worldwide license in this data to reproduce, prepare derivative works, and perform publicly and display publicly.

AlliedSignal Inc. Federal Manufacturing \& Technologies P. O. Box 419159 Kansas City, Missouri 64141-6159 
KCP-613-5970

Distribution Category UC-706

Approved for public release; distribution is unlimited.

\section{VACUUM SURFACE FLASHOVER}

AND HIGH PRESSURE GAS STREAMERS

J. M. Elizondo, M. L. Krogh, D. Smith,

D. Stoltz, and S. N. Wright, FM\&T, and

S. E. Sampayan, G. J. Caporaso, P. Vitello,

and N. Tishchenko, Lawrence Livermore National Laboratory

Published July 1997

Paper submitted to $11^{\text {th }}$ IEEE International Pulsed Power Conference June 29 - July 2, 1997

Baltimore, MD 


\title{
VACUUM SURFACE FLASHOVER AND HIGH PRESSURE GAS STREAMERS
}

\author{
J. M. Elizondo, M. L. Krogh, D. Smith, D. Stoltz, and S. N. Wright \\ AlliedSignal Federal Manufacturing \& Technologies (FM\&T)
}

\author{
S. E. Sampayan, G. J. Caporaso, P. Vitello, and N. Tishchenko \\ Lawrence Livermore National Laboratories
}

Pre-breakdown current traces obtained during high pressure gas breakdown and vacuum surface flashover show similar signatures. The initial pre-breakdown current spike, a flat constant current phase, and the breakdown phase with voltage collapse and current surge differ mostly in magnitude. Given these similarities, a model, consisting of the initial current spike corresponding to a fast precursor streamer (ionization wave led by a photoionizing front), the flat current stage as the heating or glow phase, and the terminal avalanche and gap closure, is applied to vacuum surface flashover. A simple analytical approximation based on the resistivity changes induced in the vacuum and dielectric surface is presented. The approximation yields an excellent fit to pre-breakdown time delay vs applied field for previously published experimental data. A detailed kinetics model that includes surface and gas contributions is being developed based in the initial approximation.

\section{INTRODUCTION}

Vacuum surface flashover seems to be a more complex problem than the name implies. The physics behind flashover is complex and difficult to properly model. Depending on the convenience of the model applied, or suggested by the author, some elements are included or excluded from the picture. Just like with many processes in nature, the elements that control the phenomena may come into play at once, or in stages, as a function of some external controlling parameter. Some elements are present at all times, but their influence is not triggered until some other effect develops. For instance, the surface photoelectron production may not be a factor until a threshold photon fluence is produced. This fluence may not develop until a certain external electron number density develops by thermal ionization. This paper provides the preliminary description of an ongoing development of a flashover model that is inclusive; in other words, most relevant parameters are considered within the model. This model is being developed in conjunction with the high gradient insulator technology [1,2]. The high gradient insulator consists of alternating layers of insulating and conducting film. We have experimentally demonstrated that by controlling the surface and surface effects stimulated either by electrons or photons, field gradients comparable to vacuum breakdown levels are possible $[3,4]$.

There are several papers reviewing some of the most popular models described during the last few years [5]. There are, also, many papers describing ways to enhance surface flashover holdoff voltage [6]. The most popular model describing vacuum surface flashover is based on surface secondary electron emission developing a surface avalanche. This results in that by controlling secondary electron emission (SEE), a substantial enhancement to voltage holdoff is obtained. By far the largest voltage holdoff enhancement is provided by controlling SEE. This has been done in several ways, the most popular being surface coating with oxides. This is even true in RF applications where multipactoring suppression is extremely beneficial for the lifetime of accelerator windows [7].

The results shown in this paper are only an approximation of an ongoing model development effort. A description of the physical processes involved in the model as well as the experimental/theoretical fit is presented. Preliminary calculations performed using the physical description of the proposed model yielded a good approximation to experimental data between pre-breakdown time delay and applied field.

\footnotetext{
- Operated for the United States Department of Energy under Contract No. DE-ACO4-76-DP00613.
} 


\section{DESCRIPTION OF THE MODEL}

A comprehensive model of vacuum surface flashover must include as many relevant processes as computationally possible. Some of the most popular models are based on surface secondary emission with minimum influence from the gaseous components present at the surface vicinity. A robust model cannot assume only surface effects and ignore gas and gaseous elements of the discharge. In fact, gaseous components may initiate and open the ionization path that allows energy deposition into the flashover path, and gaseous components may also be responsible for the intense luminosity observed before full current collapse [8]. One of the first suggestions that gas desorbed by electron bombardment creates a high pressure environment for a gas streamer type of breakdown was presented in the late $60 \mathrm{~s}[9,10]$. An excellent argument for a vacuum flashover model based on high pressure was suggested in the mid-80s by Eoin W. Gray [11]. The model presented in this paper follows the approach suggested by these two papers and complements them by introducing surface effects not previously considered. The model is presented in a comprehensive form by way of different medium impedance. An impedance distribution is assigned to each strong contributor: 1) dielectric subsurface, formed by the first few solid monolayers; 2) dielectric solid-gas interface, first monolayers outside the solid where adsorbed molecules reside and interact; and 3) molecular expanding flow into the measurable vacuum; this is the out-gassed material and desorbed molecules region. Each region contributes differently to the collapse of the overall impedance (or electron number density increases), and they couple in a series parallel type of arrangement. The proposed impedance distribution interacts in a unique way to initiate, develop, and sustain the current flow during flashover.

There are several elements that come into play once the dielectric is introduced in a vacuum chamber with a pair of electrodes: 1) a solid dielectric; 2) a solid-to-vacuum interface, which may be high pressure; 3) a layer of adsorbed material, strongly interacting with the first few solid monolayers; 4) a layer of desorbed and outgassed molecules, from the solid into the vacuum; 5) a region of vacuum, measured by instruments; and 6) the electrode metallic surface. This environment exists, within the gas dynamics of the molecular flow established by the vacuum pumping system, before voltage is applied to the system.

Once voltage is applied, the conditions for flashover may exist as follows: 1) the cathode surface injects electrons to the gap by explosive field emission; this emission is statistically distributed throughout the surface including the triple point; current resulting from this emission follows Child's-Lagmuir equation $[12] ; 2)$ the triple point electric field is enhanced by the dielectric mismatch at the interface following:

$$
E 2(h 1, h 2):=\frac{\varepsilon 1 \cdot U t}{\varepsilon 2 \cdot h 1+\varepsilon 1 \cdot h 2}
$$

where: $\mathrm{h} 1$ and $\mathrm{h} 2$ are the dielectric thickness and the mismatch gap at the triple point, $\varepsilon 1$ and $\varepsilon 2$ are the dielectric constants of the dielectric and the gap, and Ut is the applied voltage; 3) emission from the triple point is enhanced and results in dielectric electron injection and local electron impact ionization; 4) photons are generated by the developing ionization front [13] following a simple relation that involves the population of excited states $\mathrm{Ne}$ :

$$
\frac{d}{d t} N p h:=\delta \cdot N e-\frac{N p h}{\pi i}
$$

where $\mathrm{Nph}$ is the number of photons, $\delta$ is a multiple of the impact ionization rate and $\tau I$ is the lifetime of the excited states; 5) surface conductivity is dramatically increased, to a constant value, by photoelectron production down to the dielectric photon absorption length; 6) gas conductivity is also increased by precursor ionization and enhanced cathode photoionization [14]; 7) dielectric and gas impedance drop in a parallel configuration with a constant surface impedance in series (ahead of the propagating discharge); 8) 
the propagating discharge is dominated by surface released material and secondary electron emission strongly coupled to the surface; 9) secondary emission provides the electron number density required to initiate fast streamer precursor mechanism; 10) if the material is a semiconductor or a photo-conductor, photon density downstream of the ionization front may generate bulk photoelectrons faster than all outside the surface processes. As a consequence, the streamer "walks" into the surface producing a partial flash [15].

Table 1 shows the simplified time dependent electron number density equations for the three different sections considered to participate in the flashover process.

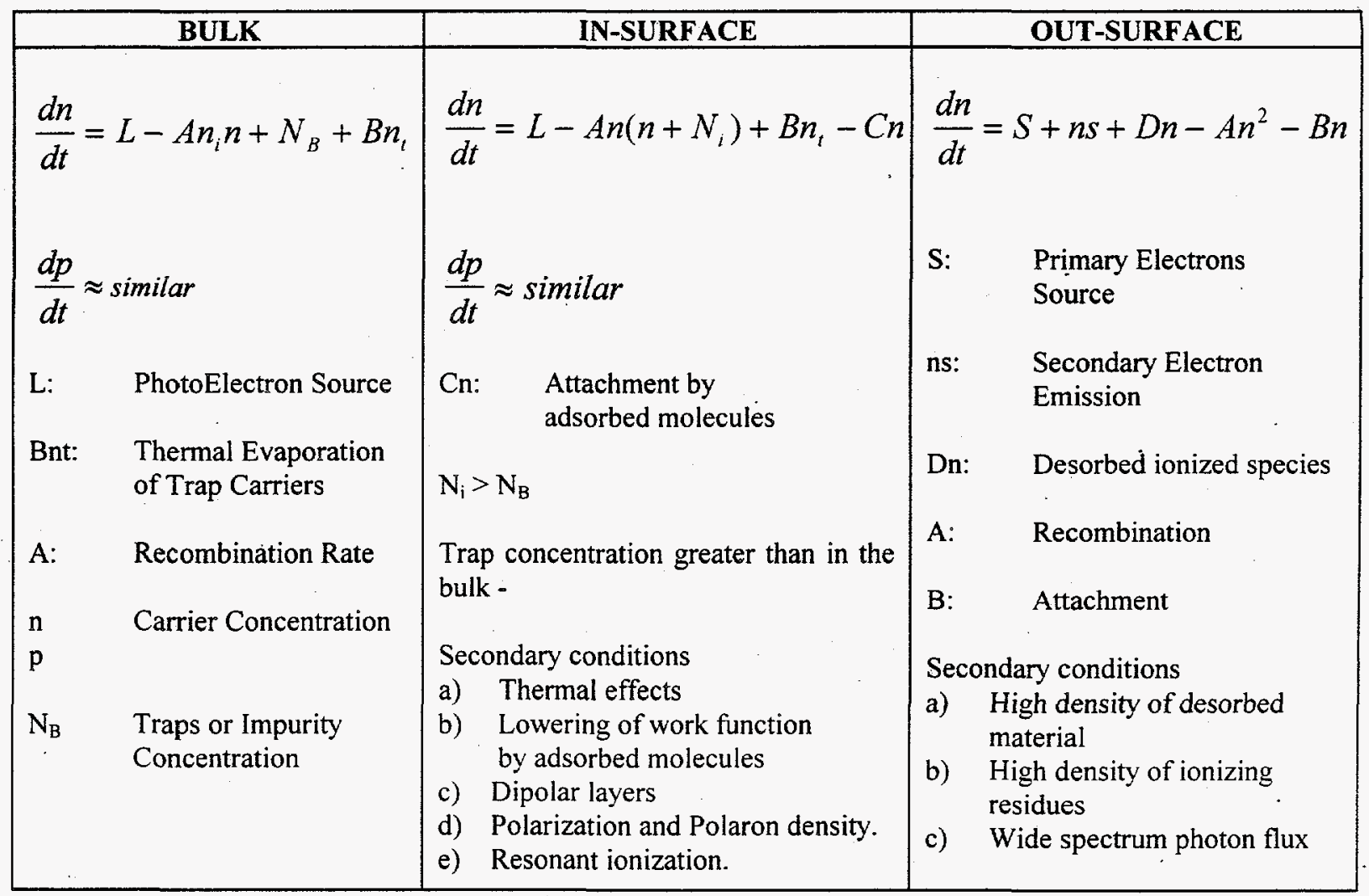

\section{MODEL APPROXIMATION RESULTS}

Based on the resistivity changing as a function of time, a simple analytical approximation to this model was developed. This was done to test the basic idea and to see if the processes involved will produce a sensible answer. The resistivity changes as a function of time based in the increasing electron number density. The electron number density increases based on several mechanisms such as 1) electron impact ionization, 2) photoionization, and 3) secondary electron production. We assumed an initial electron number density based on the surface charge left behind after flashover (SEE production is considered as the minimum electron number density required to flash) [16]; the flash propagation velocity was taken from observations [17]. The dielectric surface resistivity was compared with measurements taken on ceramic (after the sample flashover and not recovered) [18]. 
A simple approximation for the resistivity (no ion contribution) is:

$$
\rho \circ(\mathrm{t}, \mathrm{ti})=\frac{\mathrm{me} \cdot \mathrm{w}}{\operatorname{ne}(\mathrm{t}, \mathrm{ti}) \cdot \mathrm{q}^{2}}-10^{3.3} \cdot \mathrm{ohm} \cdot \mathrm{cm}
$$

where: $m e$ is the electron mass, $w$ is the collision frequency (approximated by the plasma density), $t$ and ti are the gap distance and pulse length required to calculate the electron number density ne; the constant factor $\left(10^{3.3}\right)$ represents the dielectric surface resistivity.

It has been estimated that the threshold electron number density required to sustain a streamer-like avalanche is $10^{8}$ electrons [19], with the channel radius of $0.2 \mathrm{~mm} \mathrm{[20]} \mathrm{and} \mathrm{a} \mathrm{length} \mathrm{of} 1 \mathrm{~mm}$. This corresponds to $3.18-10^{13} \mathrm{e} / \mathrm{cc}\left(3.18-10^{14} \mathrm{e} / \mathrm{cc}\right.$ with a $0.1 \mathrm{~mm}$ length). Current measurements [21], confirmed by full 2D simulations [22], set the initial electron number density for high pressure streamer formation at $10^{14} \mathrm{e} / \mathrm{cc}$. In our model the initial number density is on the order of $10^{10}-10^{11} \mathrm{e} / \mathrm{cc}$ in correspondence with the lower pressures.

The model results were compared with data relating applied electric field gradient with time delay to flashover [17]. Figure 1 shows the results of such comparison.

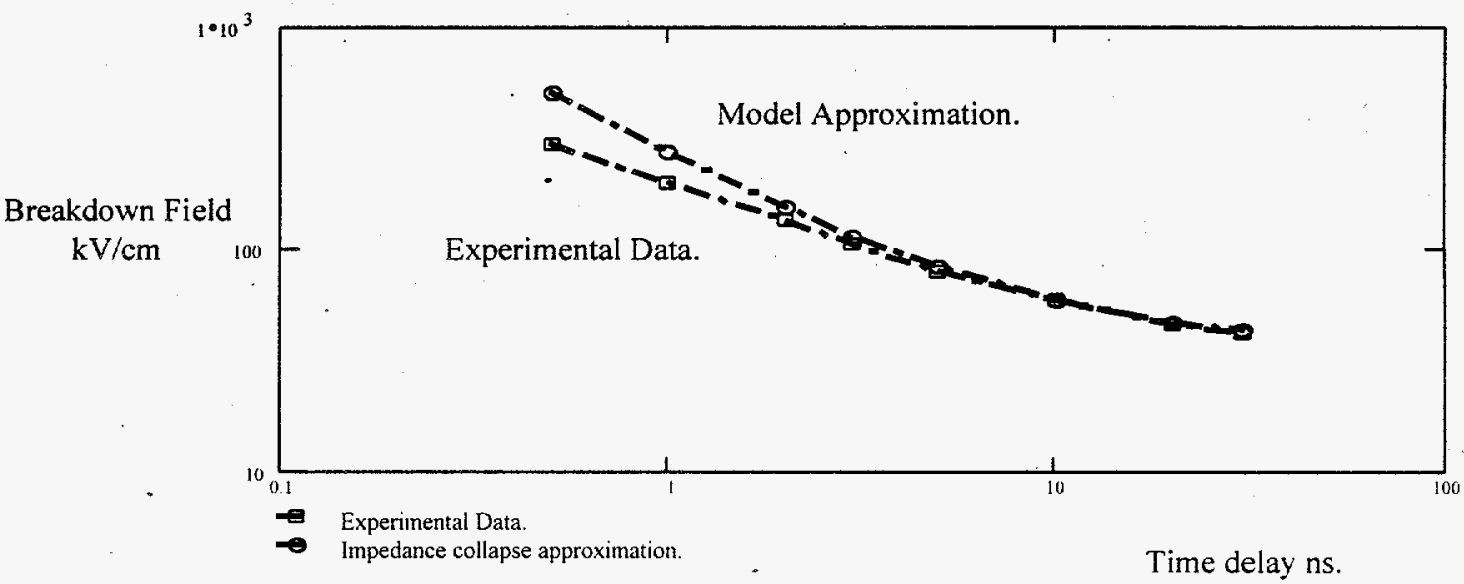

Figure 1. Comparison of model results with experimental data for Alumina insulators. The fit up to $1 \mathrm{~ns}$ is within the data scatter; the model follows the bend at long delay times.

As can be seen, the fit is within the data scatter down to $1 \mathrm{~ns}$. The fit follows the bend observed after $10 \mathrm{~ns}$ which departs from the simple $E^{-2}$ fit. The curve fit is greatly improved when a larger electron number density is initially used, but we are most interested in the long pulse regimen. Figure 2 shows the resistivity drop as a function of time for two field gradient levels; as expected, the higher the gradient, the faster the impedance collapses. This corresponds to shorter delay times at higher gradients. 


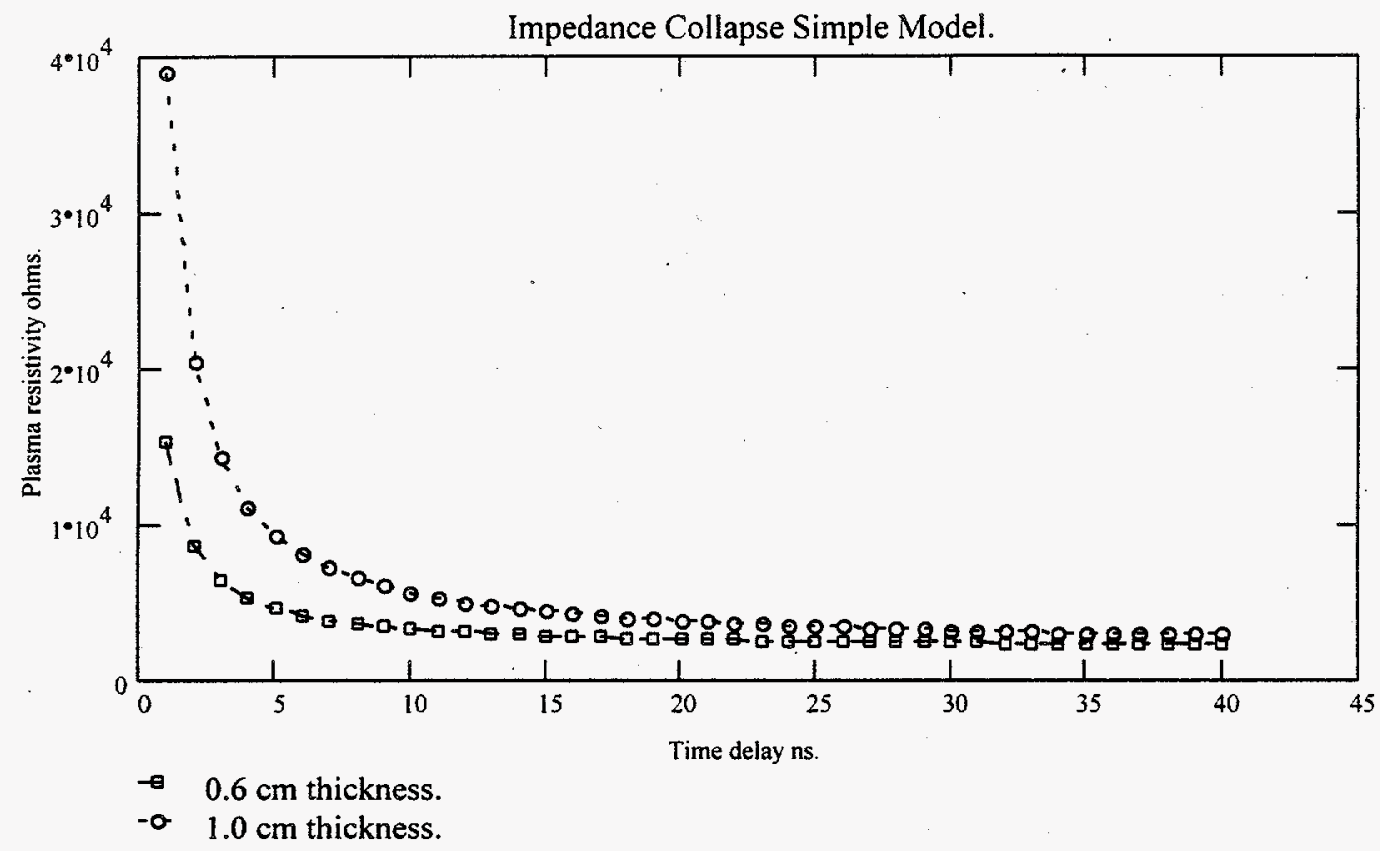

Figure 2. Resistive drop of the surface-gas interface. The model predicts the threshold impedance value for flashover.

\section{CONCLUSIONS}

A code is being developed to model surface flashover in a comprehensive manner. The formal model includes most fundamental physical processes identified throughout the years as participants of flashover. The model will gauge contributions from these processes and identify, by comparison with experimental data, those that dominate. A simple approximation, to test the validity of the model approach, was used to fit existing experimental data not completely matched by other proposed models. Experimental values and data from successful high pressure streamer formation codes were used in the approximation. It is significant to observe that the surface resistance measured, after tracks formed at the insulator surface, provide threshold value for the surface impedance required in the resistivity equation for the model approximation. Suppression of secondary electron emission produces a great improvement, in flashover strength, because a greater number of electrons are required from the triple point enhancement to initiate an out surface avalanche. The contributions from the first two equations is greatly reduced given that photon production is enhanced by electron stimulated processes. A second important prediction by the model is that the surface impedance changes faster than that of the medium with a strong dependence on the initial DC surface resistivity. The dependence is being explained elsewhere [23]. This explains the strong correlation between surface resistivity values and flashover voltages previously indicated by some researchers [10].

\section{REFERENCES}

[1] J. M. Elizondo and A. Rodriquez, Proceedings of the 1992 15th International Symposium on Discharges and Electrical Insulation in Vacuum, Vde-Verlag Gmbh, Berlin, Germany, pp. 198202.

[2] S. Sampayan, et. al., Proceedings of the 1995 Particle Accelerator Conference, (IEEE), New York, N.Y., pp. 1269-1271.

[3] J. M. Elizondo, Proceedings of the $19939^{\text {th }}$ International Pulsed Power Conference, (IEEE), Albuquerque, N.M., pp. 257-260. 
[4] S. Sampayan, et. al., Proceedings of the 1995 Particle Accelerator Conference, (IEEE), New York, N.Y., pp. 2123-2125.

[5] R. A. Anderson, 1978 Ann. Rept. CEIDP, 173-178, (1979).

[6] L. L. Hatfield, E. R. Boerwinkle, G. R. Leiker, H. Krompholz, R. Korzekwa, M. Lehr, M. Kristiansen, "Methods of Increasing the Surface Flashover Potential in Vacuum," IEEE Transactions on Electrical Insulation $13^{\text {th }}$ International Symposium on Discharges and Electrical Insulation in Vacuum (ISDEIV).

[7] T. L. Houck, G. J. Caporaso, C. C. Shang, S. E. Sampayàn, N. E. Molau, M. L. Krogh, "Measured and Theoretical Characterization of the RF Properties of Stacked, High-Gradient Insulator Material," Proceedings of 1997 IEEE Particle Accelerator Conference.

[8] H. Kirkici, "Optical Emission Characteristics of Polycrystalline Diamond During Surface Flashover in Vacuum," 1996 IEEE $17^{\text {th }}$ International Symposium on Discharges and Electrical Insulation in Vacuum, Berkeley, 1996.

[9] S. P. Bugaev, A.M. Iskol'dskii, and G. A. Mesyats, Sov. Phys. Tech. Phys. 12, 1358 (1968).

[10] A. A. Avdienko and M. D. Malev, Sov. Phys. Tech. Phys. 22, 986 (1977).

[11] Eoin W. Gray, "Vacuum Surface Flashover: A High-Pressure Phenomenon," J. Appl. Phys. 58(1), 1 July 1985.

[12] J. M. Elizondo, A. E. Rodriguez, E. M. Honig, "Characterization of an Insulated SCL Nonrelativistic Electron-beam Diode Operating at $300 \mathrm{kV} / \mathrm{cm}$," IEEE Transactions on Dielectrics and Electrical Insulation, Vol. 2, No. 3, June 1995.

[13] Penney, G. W. and Hummert, G. T., "Photoionization Measurements in Air, Oxygen, and Nitrogen," J. of Appl. Phys., Vol. 41, No. 2, pp. 572-577, February 1978.

[14] C. Wu and E. E. Kunhardt, "Formation and Propagation of Streamers in $\mathrm{N}_{2}$ and $\mathrm{N}_{2}-\mathrm{SF}_{6}$ Mixtures," Phys. Rev. A., Vol. 37, No. 11, pp. 4396-4406, June 1988.

[15] J. M. Elizondo and M. Lenzner, "Silicon and Gallium Arsenide Vacuum Surface Flashover Improvement," $15^{\text {th }}$ International Symposium on Discharges and Electrical Insulation in Vacuum, Darmstadt, 1992.

[16] C. H. DeTourreil and K. D. Srivastava, IEEE Trans. EI 8, 17, (1973).

[17] R. A. Anderson, Appl. Phys. Letts., 24, 54-56, (1974).

[18] T. Suzuki, "Flashover Voltage over Ceramics in High Vacuum," Japanese Journal of Applied Physics, Vol. 13, No. 10, October, 1974.

[19] E. W. Gray and T. A. Uhrig, IEEE Trans. Comp. Hybrids and Manuf. Tech., CHMT-3, 442-448, (1980).

[20] A. E. Rodriguez, W. L. Morgan, K. J. Touryan, W. M. Moeny, and T. H. Martin, "An Air Breakdown Kinetic Model," J. Appl. Phys. 70 (4), 15 August 1991.

[21] J. Wells, UNM MS thesis EE, 1987.

[22] A. E. Rodriguez, K. J. Touryan, and W. M. Moeny, in Proceedings of the 1989 IEEE Conference on Plasma Science, Buffalo, N.Y., 22-24 May 1989.

[23] J. Elizondo, et. al., submitted for publication to the Journal of Applied Physics, 1997. 